\title{
Development of a Micro-Hybrid System for a Three-Wheeled Motor Taxi
}

\author{
T. Hofman ${ }^{1}$, S.G. van der Tas, W. Ooms, E.W.P. van Meijl, B.M. Laugeman \\ ${ }^{1}$ (corresponding author), Eindhoven University of Technology, \\ Den Dolech 2, 5600 MB Eindhoven, The Netherlands, t.hofman@tue.nl
}

\begin{abstract}
In large cities in Asia and Africa millions of auto-rickshaws offer their taxi-services. At the same time these three-wheelers cause severe air-pollution and produce large amounts of green house gasses (carbon dioxide). The goal of the research presented in this paper is to develop a compact, robust and affordable hybrid system in order to significantly reduce the fuel consumption and emissions of auto-rickshaws. A Bajaj RE auto-rickshaw equipped with a two-stroke engine is imported from India into The Netherlands and tested on a dynamo meter regarding fuel consumption and emissions on a representative drive cycle. A fully-automated, easy-to-mount, compact and affordable micro-hybrid system has been developed with which the fuel consumption and CO2-emissions are significantly reduced (21\%) and the driver's comfort is increased.
\end{abstract}

Keywords: Hybrid Electric Propulsion System, Battery, Control Optimization, System Design Optimization, Electric Machine, Auto-rickshaw

\section{Introduction}

In large cities in Asia and Africa millions of auto-rickshaws offer their taxi-services. At the same time these three-wheelers cause severe airpollution and produce large amounts of green house gasses $(\mathrm{CO} 2)$. The drivers of these vehicles constitute mainly the lower income groups in society who earn around Rs 75-125 per day, or 1.2-2 Euro per day. Auto-rickshaws are also known as 'tuc-tucs' in Asia (see, Figure 1). Within this framework the objective of the

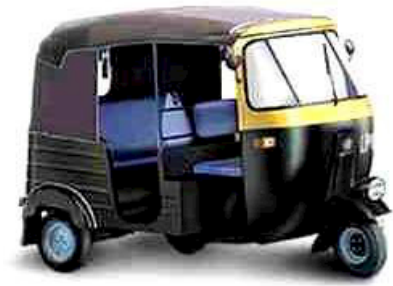

Figure 1: Three-wheeled motor taxi equipped with a 2-stroke engine [1]. project [2] is to make this existing tuc-tuc more efficient through the use of an affordable add-on hybrid system. The fuel economy improvement objectives are $40 \%-60 \%$ without loss of vehicle performance. Moreover, the hybrid tuc-tuc project objectives are:

- $\mathrm{CO} 2$-emission reduction of tuc-tucs;

- Improve air quality in Asian cities;

- Improve social and economic situation of tuc-tuc drivers (increase income);

- Stimulate innovation and inspire young entrepreneurial people.

In the year 2000 there were about 18 million petrol-engine-power two-wheelers and about 1.5 million petrol- and diesel-powered three wheelers. Since then the population is estimated to be grown at a rate of about $15 \%$ per annum [3]. If we assume that an auto-rickshaw runs approximately $50-60 \mathrm{Km} /$ day with a fuel consumption of $25-30 \mathrm{Km} / 1$, then the fuel consumption is approximately 21 per day. The corresponding CO2emissions are $21 /$ day $\cdot 2.5 \mathrm{Kg} / \mathrm{l}=5 \mathrm{Kg}$ per day. 
If a hybrid system added on to the conventional drive train would save fuel of at least $40 \%$, then the total amount of CO2-reduction for 1 million tuc-tucs would be 2 million $\mathrm{Kg}$ per day. If the $\mathrm{CO} 2$-reduction would be traded on the European market, then the saved $\mathrm{CO} 2$-emissions against 25 Euro/1000Kg [4] would be worth approximately 50 thousand Euro, and on a yearly basis (assume 300 days in operation per year) approximately 15 million Euros.

\subsection{Objectives and outline of the paper}

In literature $[5,6,3]$ other design concepts for three-wheeled vehicles can be found. In [3] a completely battery-driven rickshaw, which has been developed in India and is called Elecsha, is discussed. The electric vehicle has a zero emission range of $60-80 \mathrm{Km}$ (60\%-80\% depth-ofdischarge). The maximum speed is $30 \mathrm{Km} / \mathrm{h}$. The electric motor size is $1.2 \mathrm{~kW}$ and the battery pack consists of a 3 lead-acid batteries with a total capacity of 100 Ah with a package mass of $96 \mathrm{Kg}$. The cost price of the rickshaw in mass production is estimated to be between 70000$100000 \mathrm{Rs}$, which is approximately equal to 1100-1600 Euro respectively. A conventional rickshaw equipped with a petrol or diesel engine costs between 75000 Rs and 100000 Rs, or 1200 Euro and 1600 Euro respectively. In this design study we are aiming at a fuel saving of at least $40 \%$ for a hybrid system with a cost price in mass production between 300-600 Euro or 7.5-15 Euro per \% fuel savings. Note that LPG conversion kits cost in the same order and only reduce approximately $10 \% \mathrm{CO} 2-$ emissions. The additional cost in Euro per $\mathrm{Kg}$ $\mathrm{CO} 2$-emissions reduction per day would be approximately $((600+300) / 2) /(40 \% \cdot 5)=225$ Euro/Kg CO2 reduction. In comparison with the full-electric vehicle this would be $((1600+$ $1100) / 2) / 5=270$ Euro/Kg CO 2 reduction. Using these assumptions the hybrid system could be more cost-effective while the vehicle performance is not compromised.

In this study we present a concept design evaluation study for the innovative hybridization of a tuc-tuc and the first results of the developed micro-hybrid system are presented.

The outline of the paper will be as follows. The vehicle model and the simulated fuel saving potential using a simplified control strategy is discussed in Section 2. Note that the vehicle model including the component efficiencies is currently validated and the engine fuel efficiency map is being reconstructed. Therefore, in this paper still estimated values for the drive train component efficiencies are used to compute the fuel saving potential of a full-hybrid solution. Accordingly, the topology design options for full-hybrid system solutions are discussed in Section 3. The design and the working principle of the developed micro-hybrid system is presented in Section 4. Some preliminary fuel saving and emission reduction results of the system are shown in Section 5. Finally, in Section 6, the conclusion and future work is discussed.

\section{Vehicle model and power train}

The vehicle is equipped with a two-stroke 145.45 cc single cilinder SI engine with a maximum crankshaft power of $5.15 \mathrm{~kW}$. The maximum engine efficiency is typically $21 \%$ and $23 \%$ for an optimized engine with a LPG kit [8]. The transmission consists of a four speed manual gearbox with a reverse gear, and a wet-plate clutch. The kerb mass of the vehicle is $277 \mathrm{Kg}$ and the maximum payload is $333 \mathrm{Kg}$. In Table 1 an overview of the vehicle specifications is listed. The ac-

Table 1: Specifications: Bajaj RE 2S Petrol motor taxi

\begin{tabular}{|c|c|}
\hline Engine & Value: \\
\hline Type & $\begin{array}{l}\text { Single cylinder, 2-stroke } \\
\text { forced air cooler }\end{array}$ \\
\hline Displacement & $145.45 \mathrm{cc}$ \\
\hline Max. power, $P_{e, \max }$ & $\begin{array}{l}7.00 \mathrm{HP}, 5.15 \mathrm{~kW} \text { at } 5000 \\
\mathrm{rpm}\end{array}$ \\
\hline Max. torque, $T_{e . \max }$ & $12.1 \mathrm{Nm}$ at $3500 \mathrm{rpm}$ \\
\hline Transmission & 4 forward and 1 reverse \\
\hline Gear ratios $^{\dagger}, r_{t}$ & {$[0.20,0.34,0.54,0.89]$} \\
\hline Primary ratio $^{\dagger}, r_{p}$ & 0.88 \\
\hline Final drive ratio ${ }^{\dagger}, r_{d}$ & 0.24 \\
\hline Clutch type & Wet multi-disc type \\
\hline Brakes & $\begin{array}{l}\text { Front \& rear hydraulic } \\
\text { break system }\end{array}$ \\
\hline \multicolumn{2}{|l|}{ Weights \& Measures } \\
\hline Gross vehicle weight, $m_{v}$ & $610 \mathrm{Kg}$ \\
\hline Kerb weight & $272 \mathrm{Kg}$ \\
\hline Chassis type & Monocoque \\
\hline \multicolumn{2}{|l|}{ Dimensions } \\
\hline Overall length & $2625 \mathrm{~mm}$ \\
\hline Overall width, $W$ & $1300 \mathrm{~mm}$ \\
\hline Overall height, $H$ & $1710 \mathrm{~mm}$ \\
\hline Wheel base, $L$ & $2000 \mathrm{~mm}$ \\
\hline Ground clearance & $180 \mathrm{~mm}$ \\
\hline Turning radius & $2.88 \mathrm{~m}$ \\
\hline Tyres, $r_{w}$ & $4.00-8,4 \mathrm{PR}$ \\
\hline Roll resistance ${ }^{\ddagger}, c_{r}$ & 0.015 \\
\hline Air drag coefficient ${ }^{\ddagger}, c_{d}$ & 0.44 \\
\hline Frontal surface area $^{\ddagger}, A_{f}$ & $2.0 \mathrm{~m}^{2}$ \\
\hline \multicolumn{2}{|l|}{ Electric system } \\
\hline System voltage & $12 \mathrm{~V}$ \\
\hline Alternator output $\ddagger$ & $13.5 \mathrm{~V}, 35 \mathrm{~A}$ at $3600 \mathrm{rpm}$ \\
\hline \multicolumn{2}{|l|}{ Fuel economy } \\
\hline Mileage within a city & 18 to $20 \mathrm{Km} /$ liter (45 mpg) \\
\hline Mileage on the highway & $25 \mathrm{Km} / \mathrm{liter}(60 \mathrm{mpg})$ \\
\hline Average traveled distance & 40 to $60 \mathrm{Km} /$ day \\
\hline Maximum speed & $56-80 \mathrm{Km} / \mathrm{h}(35-50 \mathrm{mph})$ \\
\hline Fuel tank capacity & $\begin{array}{l}8 \text { liters (including } 1.4 \text { liters } \\
\text { reserve) }\end{array}$ \\
\hline Gas tank travel distance & $\begin{array}{l}145 \mathrm{Km} \text { to } 190 \mathrm{Km}(90 \mathrm{mi} \\
\text { to } 120 \mathrm{mi})\end{array}$ \\
\hline
\end{tabular}

Oil must be added to every liter at 20 to 50 $\mathrm{ml} /$ liter $(2.5 \mathrm{oz} .6 .4 \mathrm{oz} . / \mathrm{gal})$

${ }^{\dagger}$ these values are for a diesel engine. ${ }^{\ddagger}$ these values are estimated.

tual fuel efficiency map is also yet not available (the fuel mass-flow of the tuc-tuc engine is be- 
ing measured). Therefore, the engine efficiency map of a $1.01 \mathrm{SI}$ engine is downsized to meet the specifications of the $145 \mathrm{cc} 2$-stroke engine. Thereby, the efficiency values of the 1.0-1 engine are linearly down-scaled, where the maximum efficiency becomes $21 \%$ corresponding to the typical maximum value of a two-stroke engine. The transmission and the final drive efficiency are both average constant $95 \%$ assumed.

\subsection{Drive cycle and drive power demand}

In literature [3] is found that auto-rickshaws in the traffic conditions in inner-city areas run at only $15-20 \mathrm{Km} / \mathrm{h}$. This cause a severe emission pollution, since the conventional power trains are designed to run efficiently at $40-45 \mathrm{Km} / \mathrm{h}$. Furthermore, the pollution is increased more by frequently starting and stopping of the rickshaw in the dense traffic. Clearly, the drive cycle plays an important role in the design of the hybrid drive train, since it determines the operations points of the power source. Furthermore, on an average the auto-rickshaws travel about $50-60 \mathrm{Km}$ per day. The Federal Test Procedure FTP-75 has been used to mimic the usage of the rickshaw, because of its more dynamic behavior compared to the mild European drive cycle (NEDC). In addition, the FTP-75 has been modified by reducing the top speed to $50 \mathrm{Km} / \mathrm{h}$. The average drive cycle speed is $18.7 \mathrm{Km} / \mathrm{h}$, which correspond to the average inner-city traffic situations. Using this drive cycle and the vehicle parameters as listed in Table 1, the vehicle wheel torque can be calculated as follows:

$$
T_{v}(t)=m_{v} \cdot g \cdot c_{r} \cdot r_{w}+\frac{1}{2} \cdot \rho \cdot c_{d} \cdot A_{f} \cdot \omega_{v}(t)^{2} \cdot r_{w}^{3},
$$

with the wheel speed

$$
\omega_{v}(t)=v(t) / r_{w} .
$$

The drive power demand becomes,

$$
P_{v}(t)=T_{v}(t) \cdot \omega_{v}(t)
$$

In Figure 2, the modified FTP-75 and the drive power demand calculated with Equation (3) as a function of time is shown. The fuel economy using the drive power demand, the drive cycle, and pre-scribed gear box shifts can be calculated. In addition, the maximum output of the alternator is estimated to be $13.5 \mathrm{~V} \cdot 35 \mathrm{~A}=438 \mathrm{~W}$. For the simulation an average electrical load of 200 $\mathrm{W}$ is assumed. The fuel economy in $1 / 100 \mathrm{Km}$ as a function of time is shown in Figure 3. The fuel economy over the modified FTP-75 becomes 3.6 $1 / 100 \mathrm{Km}$, or $27.9 \mathrm{Km} / 1$. Idle fuel cut-off is assumed during braking. If the engine is stopped at vehicle standstill, then an absolute or relative fuel saving could be realized of $0.251 / 100 \mathrm{Km}$ or approximately $7 \%$ respectively. The fuel consumption for engine restart is not included. The fuel economy with start-stop and idle fuel cut-off during braking is $3.3 \mathrm{l} / 100 \mathrm{Km}$, or $30.0 \mathrm{Km} / 1$.
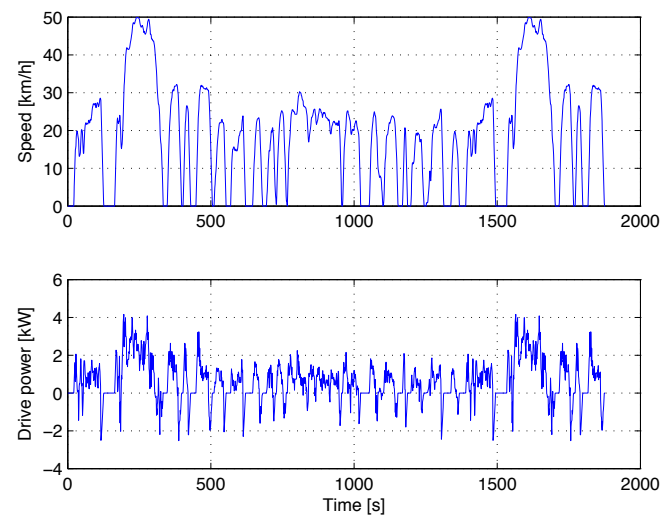

Figure 2: Drive cycle and power demand as a function of time.

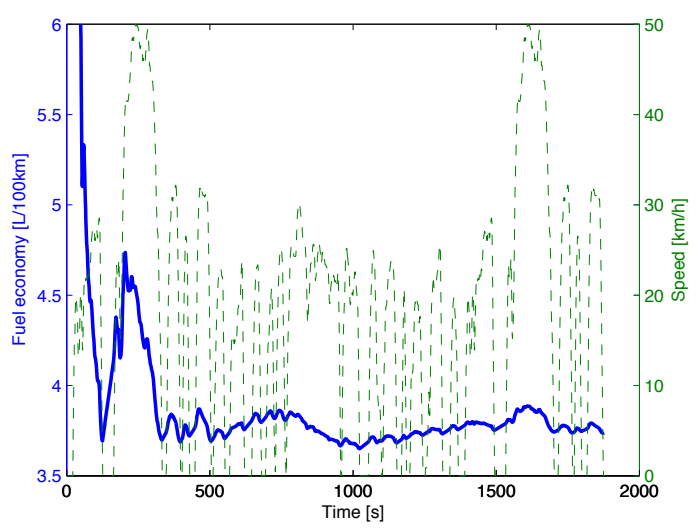

Figure 3: Fuel economy and drive cycle as a function of time.

\subsection{Simulated fuel saving potential}

The fuel saving potential could be improved by brake energy recuperation and re-use this energy, denoted as $E_{B E R}$, for electric driving. The elec-

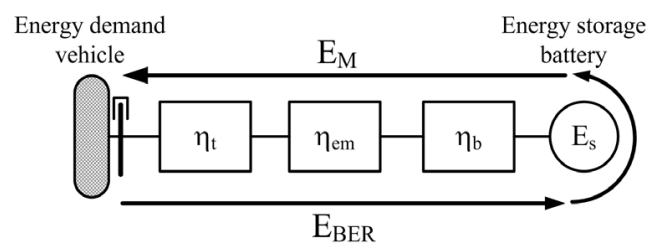

Figure 4: Energy flows during regenerative braking and electric driving.

tric energy used for driving is denoted as $E_{M}$. In Figure 4, the energy flow paths from the vehicle wheel to the battery storage system are shown. The regenerative brake energy is calculated over 
the drive cycle with time length $t_{f}$ with

$$
E_{B E R}=-\int_{0}^{t_{f}} f_{b r} \cdot \min \left(0, P_{v}(t)\right) \cdot \eta_{t} \cdot \eta_{e m} \cdot \eta_{b} \cdot d t,
$$

and the required propulsion energy for electric driving is calculated with, for propulsion during electric driving. In Figure 5 , the operation points of the electric machine over de drive cycle for the electric-only modes are plotted. The maximum drive power up to which the rickshaw is propelled by the electric machine is $476 \mathrm{~W}$ and the maximum braking power at the wheels is $-1.25 \mathrm{~kW}$. If the electrical

$$
E_{M}=\int_{0}^{t_{f}}\left(\min \left(\frac{\max \left(0, P_{v}(t)\right)}{\left(\eta_{t} \cdot \eta_{e m} \cdot \eta_{b}\right)}, P_{M}\right)-\alpha \cdot P_{M}\right) \cdot d t
$$

under the condition that the discrete variable $\alpha \forall t=\left[0, t_{f}\right]$ becomes,

$$
\alpha=\left\{\begin{array}{l}
1, \text { if } \frac{\max \left(0, P_{v}(t)\right)}{\left(\eta_{t} \cdot \eta_{e m} \cdot \eta_{b}\right)} \geq P_{M} \\
0, \text { elsewhere }
\end{array}\right.
$$

The storage power up to which the brake energy can be used for pure electric driving, denoted as $P_{M}^{o}$, becomes,

$$
P_{M}^{o} \in\left\{\begin{array}{l}
E_{B E R}-E_{M}\left(P_{M}^{o}\right)=0 \mid \\
P_{M}=\left[0, \frac{\max \left(P_{v}(t)\right)}{\left(\eta_{t} \cdot \eta_{e m} \cdot \eta_{b}\right)}\right] \in \mathbb{R}^{+} \wedge \\
0 \leq P_{M} \leq-\min \left(P_{v}(t)\right) \cdot f_{b r} \cdot \eta_{t} \cdot \eta_{e m} \cdot \eta_{b}
\end{array}\right.
$$

In Table 2 the required electric machine size $(\mathrm{kW})$ based on the maximum generative braking power, i.e.,

$$
P_{e m}=-f_{b r} \cdot \min \left(P_{v}(t)\right) / \eta_{t},
$$

and the fuel economy improvement (including start-stop at vehicle stand still) are shown as a function of regenerative brake fraction $f_{b r}$. The transmission $\eta_{t}$, the electric motor $\eta_{e m}$ and battery efficiency $\eta_{b}$ are $98 \%, 85 \%$, and $80 \%$ average constant assumed. The engine is assumed to shut off and has no drag losses during braking and electric driving. It can be observed, that

Table 2: Fuel saving potential as a function of regenerative brake fraction and electrical loads.

\begin{tabular}{lclcll}
\hline & & \multicolumn{2}{l}{ Fuel use $(\mathrm{Km} / \mathrm{l})$} & \multicolumn{2}{c}{ Rel.value $(\%)$} \\
$f_{b r}(\%)$ & $P_{\text {em }}(\mathrm{kW})$ & $200 \mathrm{~W}$ & $0 \mathrm{~W}$ & $200 \mathrm{~W}$ & $0 \mathrm{~W}$ \\
0 & 0 & 27.9 & 31.1 & $100 \%$ & $100 \%$ \\
$25 \%$ & 0.6 & 30.7 & 35.6 & $110 \%$ & $114 \%$ \\
$50 \%$ & 1.2 & 31.8 & 37.4 & $114 \%$ & $120 \%$ \\
$75 \%$ & 1.9 & 32.5 & 38.5 & $116 \%$ & $124 \%$ \\
$100 \%$ & 2.5 & 33.3 & 40.0 & $119 \%$ & $129 \%$ \\
\hline
\end{tabular}

the fuel saving potential and the required electric machine size are strongly affected by the regenerative brake fraction. The total relative fuel saving potential with a $1.2 \mathrm{~kW}$ electric machine size, 50\% regenerative brake fraction including start-stop, engine off and disengaged during electric braking and driving, and $200 \mathrm{~W}$ electrical loads becomes $14 \%$. Although, the electric machine is specified at $1.2 \mathrm{~kW}$ only $486 \mathrm{~W}$ is used

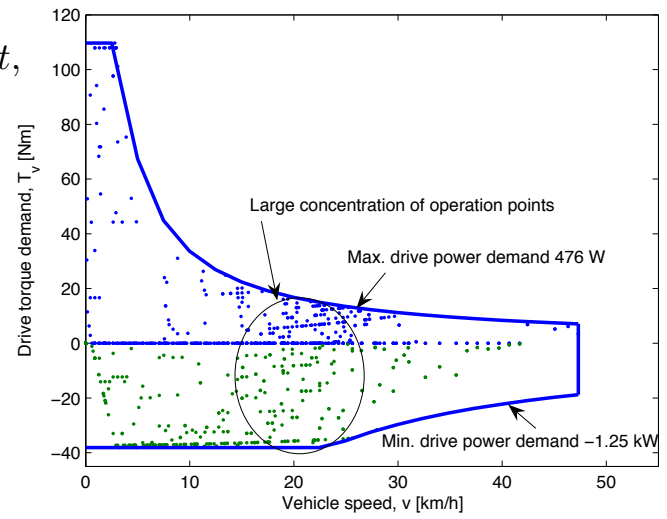

Higure 5: Operation points of the electric machine. flectric machine size is $1.2 \mathrm{~kW}$ with a regenerative brake fraction $f_{b r}=50 \%$.

loads are zero, then the fuel economy improvement is $20 \%$, which is still too low because to objective is to realize at least $40 \%$ fuel saving. However, the vehicle model used in this section needs to validated and the strategy is not optimal and the fuel saving could be further improved, which is defined as future research. Furthermore, as will be shown in Section 5, that the idle startstop function without fuel cut-off during braking only already fuel consumption reduction gives of $14.1 \%$. This in contrary to the $7 \%$ estimated on the modified FTP-75 in this section. It is likely that the engine efficiency estimated is too high in this section, and, therefore, the actual fuel savings for the full-hybrid solution are also expected to be much higher.

\subsection{Energy storage specification}

Many different battery technologies are available on the market, e.g., Lead-Acid SLA, NiCd, $\mathrm{NiMH}, \mathrm{Li}$-ion, Li-polymer battery technologies. The Lead-Acid batteries are safe, but have lower energy and power density specifications compared to the other battery technologies. NiMH battery, which is more expensive, has a good efficiency has become a mature technology and is a well-accepted storage technologie for hybrid vehicle applications. Li-ion batteries have a high energy, power density and efficiency specification, but are expensive. This type of battery have a narrow overcharge tolerance. Continuously charging over the maximum voltage limitation would damage the battery performance (cycle life) and could result in firing, or explosion. In Table 3 an overview of different battery specifications is shown [9]. Among Li- 
Table 3: Battery technologies

\begin{tabular}{llll}
\hline Battery & $\mathrm{Wh} / \mathrm{Kg}$ & $\mathrm{W} / \mathrm{Kg}$ & Cycles \\
Lead-acid & 35 & 180 & 600 \\
NiCd & 50 & 120 & 1500 \\
NiMH & 60 & 200 & 1000 \\
Li-ion & 135 & 430 & 1200 \\
\hline
\end{tabular}

polymer technologies the lithium iron phosphate (LiFePO4) is seen as a suitable battery technology for large capacity and high power applications. The LiFePO4 is characterized by faster charging (two times faster), a large overcharge tolerance $(0.7 \mathrm{~V}$ from it charging voltage plateau $3.4 \mathrm{~V})$, and a longer cycle life (2000 cycles, five times larger) compared to conventional Li-ion batteries. However, these batteries are still relative expensive, i.e., approximately 500 Euro/kWh. On the Asian market LiFePO4 batteries are available. In this example we have selected the Li-polymer battery with a nominal voltage of $48 \mathrm{~V}$ and a capacity of $15 \mathrm{Ah}$. The energy density is $90 \mathrm{Wh} / \mathrm{Kg}$ or $116 \mathrm{Wh} / \mathrm{l}$. The maximum continuous discharging current is 50 A.

The traveled distance of the modified FTP-75 cycle is $9.7 \mathrm{Km}$, which corresponds to $15 \%-20 \%$ of the total traveled distance per day. Given the Li-polymer battery specifications, a maximum Depth-of-Discharge (DOD) of $60 \%$ the maximum stationary vehicle speed at which the rickshaw is propelled with zero emission can be calculated. If the same average constant component efficiencies as in the previous section are assumed, then the maximum reachable stationary vehicle speed becomes $23 \mathrm{Km} / \mathrm{h}$. This value is equal to the average non-zero drive cycle speed of the modified FTP-75.

For comparison the hybrid rickshaw specifications based on the simulation results, are compared with the full-electric rickshaw Elecsha [3]. In Table 4 the main specifications are shown. From an energy efficiency point of view $(\mathrm{Wh} / \mathrm{km})$, the Elecsha appears to perform better than the hybrid electric rickshaw. However, if the vehicle mass of the hybrid electric rickshaw is reduced to $410 \mathrm{Kg}$, then the energy efficiency becomes $234 \mathrm{Wh} / \mathrm{Km}$, which is close to the Elecsha. This discrepancy is expected to be reduced further by optimal control of the power sources. Moreover, the performance of the hybrid electric vehicle is expected to be higher. Note that the energy required to drive the vehicle in traction mode (wheel torque $T_{v}(t)>0$ ) over the drive cycle is $48 \mathrm{Wh} / \mathrm{km}$, and $33 \mathrm{Wh} / \mathrm{km}$ if all brake energy is recuperated with $100 \%$ efficiency. The conventional rickshaw has an energy efficiency of approximately $8.47 \cdot 10^{3} / 27.9=313 \mathrm{Wh} / \mathrm{km}$ with a caloric value of petrol $8.47 \mathrm{kWh} / 1$. Maintenance and battery replacement costs can be severe design penalty. For the Elecsha the battery replacement costs are $15000 \mathrm{Rs}$, or 237 Euro for every other year. Optimal selection of the battery technology, including criteria such as replacement costs, besides efficiency, and power / energy density specifications, is also defined as future research.

Table 4: Comparison of the full-electric and the Hybrid-Electric Rickshaw (HER)

\begin{tabular}{|c|c|c|}
\hline & ELECSHA & HER \\
\hline GVW & $410 \mathrm{Kg}$ & $577 \mathrm{Kg}$ \\
\hline \multirow[t]{3}{*}{ ZER } & $60-80 \quad \mathrm{Km}$ & $9.7 \mathrm{Km} \quad(60 \%$ \\
\hline & $(60 \%-80 \%$ & DOD) \\
\hline & DOD) & \\
\hline Top speed & $30 \mathrm{Km} / \mathrm{h}$ & $65 \mathrm{Km} / \mathrm{h}$ \\
\hline Battery type & Exide & Li-polymer \\
\hline & Acid & \\
\hline weight & $96 \mathrm{Kg}$ & $8 \mathrm{Kg}$ \\
\hline capacity & $100 \mathrm{Ah}$ & $15 \mathrm{Ah}$ \\
\hline specific power & $7.95 \mathrm{~W} / \mathrm{Kg}$ & $300 \mathrm{~W} / \mathrm{Kg}$ \\
\hline energy density & $39.7 \mathrm{Wh} / \mathrm{Kg}$ & $90 \mathrm{Wh} / \mathrm{Kg}$ \\
\hline Voltage & $36 \mathrm{~V}$ & $48 \mathrm{~V}$ \\
\hline Cycle life & $\begin{array}{l}150-200 \text { cycles } \\
(60 \% \text { DOD) }\end{array}$ & 2000 cycles \\
\hline Charge time & $10-12 \mathrm{~h}$ & $2 \mathrm{~h}$ \\
\hline Motor & $1.2 \mathrm{~kW}$ PMDC & $1.2 \mathrm{KW}$ \\
\hline Energy efficiency & $220 \mathrm{Wh} / \mathrm{km}$ & $275 \mathrm{Wh} / \mathrm{km}$ \\
\hline
\end{tabular}

\section{Topology optimization}

In addition to the component sizing and control optimization, the topology selection also plays an important role in the overall hybrid drive train optimization. In Figure 6, an overview is given of different locations of coupling of the hybrid system to the drive train. If more hybrid func-

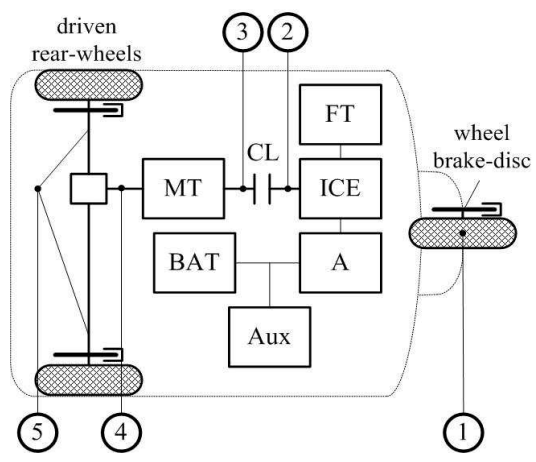

Figure 6: Overview topology design options for parallel hybrid drive train. The numbers indicate a possible location of the hybrid system. ICE $=$ Internal Combustion Engine, FT = Fuel Tank, CL = wet-plate clutch, MT = Manual Transmission, BAT = Battery, Aux $=$ Auxiliaries, $\mathrm{A}=$ Alternator.

tions (or hybrid driving modes) can be used, then the fuel saving potential increases. Depending the topology some of the hybrid functions can be utilized very well and other functions raise difficulties or are impossible. In Table 5 an overview 
is given of the pro's and con's of the different topologies. From this qualitative comparison it

Table 5: Topology Design Options

\begin{tabular}{llllll}
\hline Topology & 1 & 2 & 3 & 4 & 5 \\
Regenerative braking & ++ & - & + & + & + \\
Electric driving & ++ & $\emptyset$ & + & ++ & ++ \\
Motor-assisting & + & + & + & ++ & ++ \\
Charging during driving & - & ++ & ++ & + & + \\
Start Stop & $\emptyset$ & ++ & + & $\emptyset$ & $\emptyset$ \\
Compact & - & + & + & - & - \\
Easy to mount & ++ & - & - & - & + \\
\hline Score/Max.Score: & $\mathbf{4 3 \%}$ & $29 \%$ & $\mathbf{4 3 \%}$ & $29 \%$ & $\mathbf{4 3 \%}$ \\
\hline Legend: ++ very good, $+=$ good, & & & \\
$-=$ bad, $\emptyset=$ not possible & & & &
\end{tabular}

can be concluded that topology 1,3 , and 5 perform the same and are therefore favorable. However, detailed analysis of these topologies for the full-hybrid solutions needs to be done, which is also defined as future research. In the following sections, the design of the developed microhybrid systems for a 2-stroke Bajaj tuc-tuc is presented. Although, with a full-hybrid solution the full saving potential is likely to be much higher, the investment costs are also higher compared to a micro-hybrid system.

\section{Design and working principle of the micro-hybrid system}

The micro-hybrid system is designed in order to reduce fuel consumption and emissions of a Bajaj 2RE three wheeler. Moreover, the microhybrid system is specially designed as a retrofit 'kit', i.e., the kit can be installed in a used tuctuc. The main working principle of the microhybrid system is the start-stop functionality. Especially, in crowded city areas (see, Figure 7), vehicles are frequently standing still in front of traffic lights and in traffic jams. During these

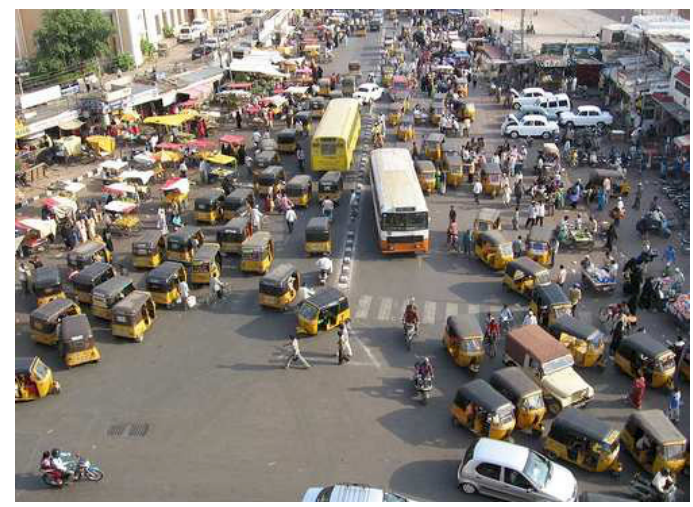

Figure 7: Auto-rickshaws during high traffic hours.

periods, no power from the engine is requested and engine idling is therefore a waste of fuel and the engine produces unnecessary polluting emissions. The micro-hybrid system is able to stop the engine from running when no power is requested and start the engine quickly again when the driver is going to drive away. In order to stop the engine, the electric circuit of the sparkplug will be opened and further ignitions will be prevented. Due to the friction of the piston and the compression of the fuel mixture, the engine stops. As soon as the driver is going to drive away, the micro-hybrid system will start the engine within a very short time (much less than 500 $\mathrm{ms}$ ) instance where after it can be used to propel the vehicle.

Figure 8 shows the motor compartment and drive train of the tuc-tuc and the designed micro-hybrid system prototype installed on the engine. The micro-hybrid system is connected to the flywheel housing and the flywheel itself. There are a couple reasons for this position: (i) the system must be connected to the crankshaft, (ii) the flywheel is not fully covered in the original engine, and (iii) virtually no changes have to be made on the original engine in order to connect the microhybrid system.

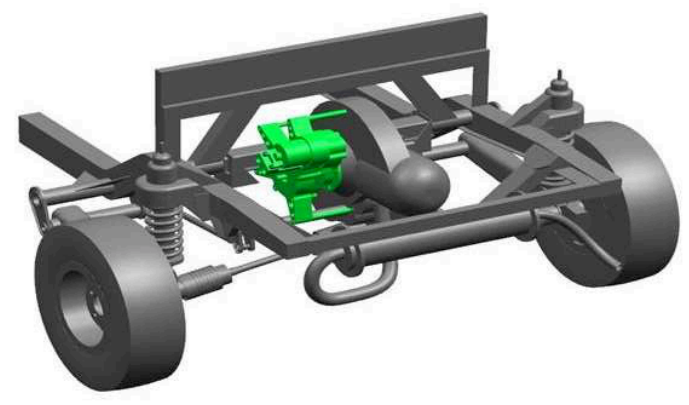

Figure 8: Original motor compartment with the micro-hybrid system (green) connected to the engine.

Figure 9 shows an exploded view of the mechanical part of the micro-hybrid system. The used electric machine for the prototype is a $600 \mathrm{~W}$ brushed DC motor that operates on $12 \mathrm{~V}$ nominal (1). This electric machine is mounted on a frame (3) and kept in place with a holder (2). The frame has a couple functions: (i) it functions as housing for the gear set, (ii) as connection for the electric machine and (iii) as connection for the hybrid kit on the original engine with the connectors $(4)$. The gear set $(7,12,11)$ is needed to adapt the angular velocity of the electric machine to the angular velocity of the engine and to increase the torque that is needed to start the engine. The requested torque depends on the acceleration of the crankshaft and flywheel, the compression of the air/fuel mixture, and the friction of the piston within the cylinder. The final gear (11) is connected to the axle (9), which is connected to the flange (10), which is mounted on the flywheel. This final gear (11) runs freely in 
one direction, and allows to run the engine without driving the electric machine thereby eliminating additional friction losses. For the prototype

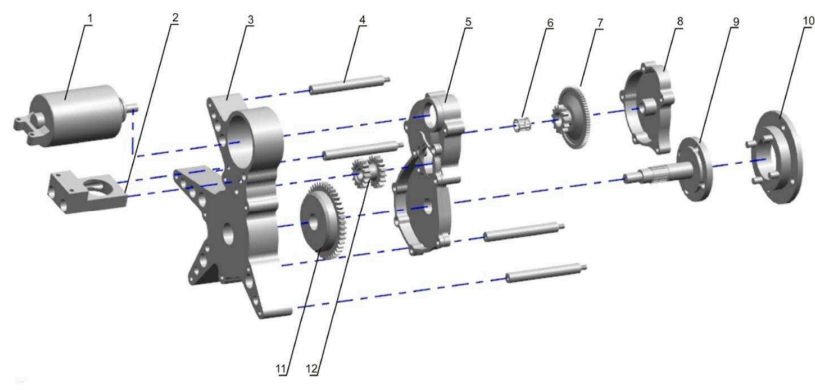

Figure 9: Exploded view of the micro-hybrid system.

of the micro-hybrid system the electric machine is over-dimensioned in terms of power. Reason for this was the availability of the system and the increased likelihood that the system works. In addition, the overpowered start system is able to decrease the starting time for the engine. A more powerful motor is able to accelerate the engine at a higher rate than a smaller, less powerful motor. Future research will focus on the optimization of electric machine size on the following aspects: starting time (which is also controlled with the ignition system), efficiency, and costs. The gear set depends on the electric machine specifications and will be determined after the electric machine optimization. In Figure 10 a picture shown of some manufactured mechanical parts of the micro-hybrid system prototype.

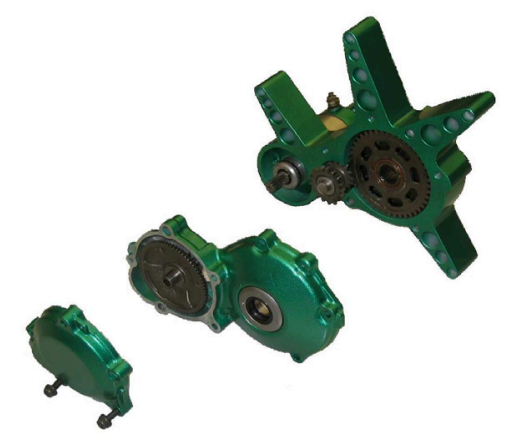

Figure 10: Picture of some manufactured mechanical parts of the micro-hybrid system prototype.

\section{Performance of the micro- hybrid system}

By stopping the engine from running at moments where no drive power is requested, will prevent unnecessary emissions and fuel consumption. In order to simulate the usage of the tuctuc within a crowded city, a drive cycle has been constructed (based on measurements performed in India). This drive cycle is plotted in the upper part of Figure 11 and shows the speed $(\mathrm{m} / \mathrm{s})$ as function of time. During the drive cycle with a total time of 707.6 seconds, the speed is equal to $0 \mathrm{~km} / \mathrm{h}$ for 234 seconds (idling time). This is plotted in red in the lower part of Figure 11. The periods where no power is requested from the engine do not only contain the idling periods, but also the phases where the tuc-tuc is coasting or decelerating. The periods where no engine power is required is indicated with the green line. The total amount of time where no engine power is requested is 301.3 seconds on this cycle.
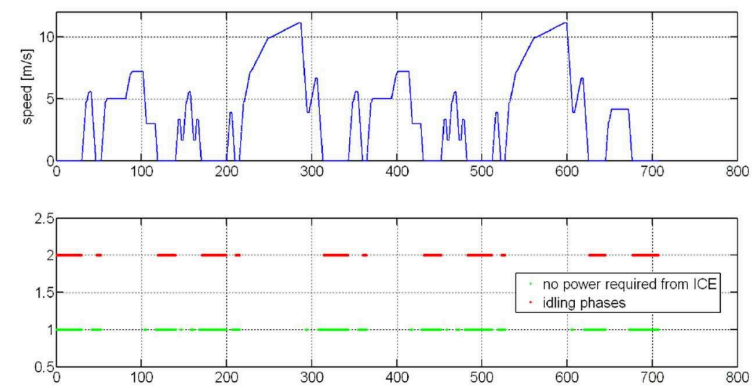

Figure 11: Drive cycle (blue) with idling phases indicated with a red line and zero power phases indicated with a green line.

\subsection{Fuel consumption and emission re- duction potential}

Using the start-stop function of the micro-hybrid system, on the drive cycle as shown in Figure 11, implies that $14.1 \%$ can be saved with shutting off the engine during the idling phases and $20.7 \%$ (or 33 grams of fuel) by stopping the engine when no propulsion power is requested, e.g., during braking. Figure 12 shows the fuel consumption of the tuc-tuc during the first part of the drive cycle with (red) and without (blue) the effect of the micro-hybrid system during the idling phases. It can be observed that the fuel consumption during the idling periods reduces to $0 \mathrm{~g} / \mathrm{s}$ with the micro-hybrid system, while the original fuel consumption is approximately $0.1 \mathrm{~g} / \mathrm{s}$ during these periods. 


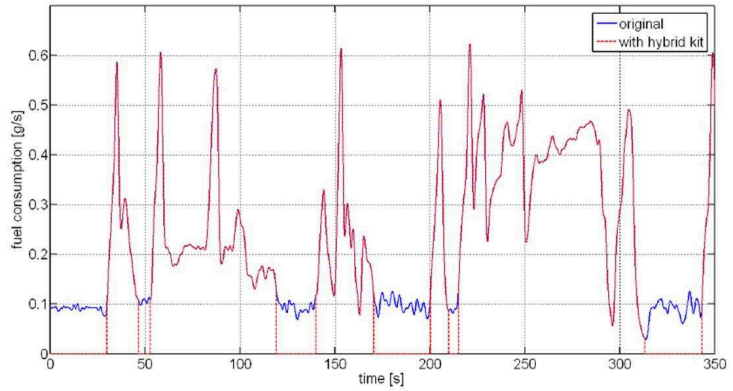

Figure 12: Fuel consumption of the original engine and with the micro-hybrid system during the drive cycle.

\section{Conclusion and Future work}

In this paper the design problem of a threewheeled motor taxi and the impact of hybridization on fuel consumption and $\mathrm{CO} 2$-emission reduction for these types of vehicles is discussed. Using a basic control strategy, the effect of component sizing and regenerative brake fraction on the fuel economy is investigated. A fully-automated, easy-to-mount, compact and affordable micro-hybrid system has been developed with which the fuel consumption and CO2emissions can be significantly reduced $(21 \%)$ and the driver's comfort is increased. Currently, the micro-hybrid system is tested more intensively in the automotive engineering laboratory of the Eindhoven University of Technology and the control system is further optimized. In the mid of July 2009 the first real field test with the microhybrid system at the SRM University in Chennai, India are expected. In future research, the microhybrid system will be redesigned (in order to further increase robustness, minimization of component specifications, and reduce costs by component integration) and full hybridization (including regenerative braking and electric driving) of the Bajaj RE2 resulting in more fuel saving potential will also be investigated.

\section{Acknowledgments}

This study is part of the student competition, referred to as the "Hybrid TuK-TuK Battle", which is a research project at the Technische Universiteit Eindhoven in The Netherlands within the section Control Systems Technology of the Department of Mechanical Engineering. The project is financially supported by the Technische Universiteit Eindhoven, Orion, Tegema, Provincie Noord-Brabant, Rabobank, Brooks, Drivetrain Innovations, Duurzaam Eindhoven.

\section{References}

[1] Bajaj, “www.auto-rickshaw.com,” 2008.

[2] Enviu Foundation, "Rules and regulation hybrid tuktuk battle 2008," Rotterdam, The Netherlands, January 2008.

[3] A. Rajvanshi, "Cycle rickshaws as a sustainable transport system for developing countries," Human Power, Technical journal of the IHPVA, no. 49, pp. 15-18, 2000.

[4] PointCarbon, "http://www.pointcarbon.com/," 2008.

[5] F. Caricchi, L. D. Ferraro, F. G. Capponi, O. Honorati, and E. Santini, "Three-wheeled electric maxi-scooter for improved driving performance in large urban areas," in Proc. of the IEEE Electric Machines and Drives Conference, vol. 3, June 2003, pp. 1363 1368.

[6] M. Alam, T. Moeller, and A. Maly, "Converions of an Indian three weeler scooter into a hybrid fuel cell Ni-MH battery vehicle and validation of the vehicle model for the Bajaj three wheeler scooter," in Proc. of the IEEE Conference on Electric and Hybrid Vehicles, 2006.

[7] M. Loganathan, P. Manivannan, and A. Ramesh, "Study on manifold injection of LPG in two stroke SI engine," Indian journal of engineering and materials sciences, vol. 13, no. 2 , pp. 95-102, 2006.

[8] L. Guzzella and A. Sciarretta, Vehicle Propulsion Systems - Introduction to Modeling and Optimization. Springer-Verlag, Berlin Heidelberg, 2005.

\section{Authors}

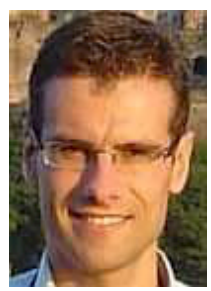

T. (Theo) Hofman received his M.Sc.- (with honors) and Ph.D.degree in Mechanical Engineering from Eindhoven University of Technology, Eindhoven. Since September 2007, he is a postdoctoral fellow with the Control Systems Technology group. His research interests are modeling, design, and control of hybrid and electric technologies for propulsion systems. 

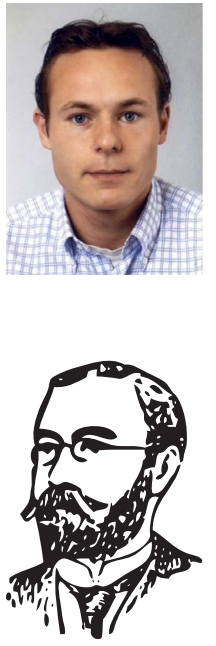

W. (Wesley) Ooms received his B.Sc.-degree in Mechanical Engineering from Eindhoven University of Technology, Eindhoven, The Netherlands, in 2006.

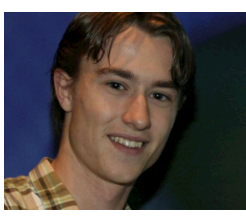

E.(Erik) W.P. van Meijl received his B.Sc.-degree in Mechanical Engineering from Eindhoven University of Technology, Eindhoven, The Netherlands, in 2009.

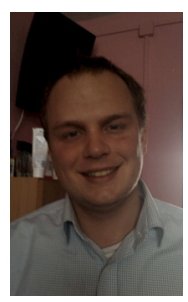

B.(Bas) M. Laugeman received his B.Sc.-degree in Technology Management from Eindhoven University of Technology, Eindhoven, The Netherlands, in 2005. 